\title{
NOTA PRÃTICA
}

\section{TRATAMENTO KENNY DA PARALISIA INFANTIL}

\author{
EXCERTOS DE RELATORIO DA COMISSAO FORMADA PELA AME- \\ RICAN MEDICAL ASSOCIATION, PUBLICADO NO JOURNAL OF THE \\ AMERICAN MEDICAL ASSOCIATION 125: $466-469$ (junho, 17) 1944.
}

Trata-se do parecer lido perante a $94 .^{\text {a }}$ sessão anual da American Medical Association, em 15 junho 1944, e redigido pela Comissão de Investigação do Tratamento Kenny da Poliomielite, organizada pela Secçāo de Cirurgia Ortopédica, constituída por R. K. Ghormley, E. L. Compere, J. A. Dickson, R. V. Funsten, J. A. Key, H. R. McCarroll e H. C. Schumm, os quais representaram a Secção de Ortopedia da A.M.A., a American Academy of Orthopedic Surgeons e a American Orthopedic Association. A Comissão visitou dezesseis clínicas em seis cidades, examinando cêrca de 740 doentes, dos quais 650 tratados pelo método Kenny. Alguns casos provinham de epidemias antigas, mas a maioria adoecera depois de 1940.

E criticado, inicialmente, o qualificativo de "ortodoxo", dado por Kenny aos outros processos terapêuticos, porquanto existem vários sistemas de tratamento e, além disso, já Lovett, em 1917 (portanto muito antes de Kenny) preconizara a hidrotermoterapia e a reeducação muscular como "tentativa para o paciente enviar um impulso voluntário para contrair o músculo", e considerara os meios de contenção como meramente protetores. E analisado, a seguir, o conceito Kenny, a propósito da paralisia infantil, que, conforme foi descrito por Pohl, baseia-se em quatro pontos: 1) Espasmo muscular, lesão inicial da moléstia, responsável pelas sequielas. A Comissão afirma que, embora o espasmo exista nos primeiros estádios da enfermidade, desaparece em geral espontâneamente; pode haver espasmo residual, porém nunca constituirá causa da paralisia; a Comissão também estabelece que êsse sinal precoce já havia sido reconhecido há muito, e era tido como parte integrante da fase aguda da paralisia infantil. 2) Alienação mental, ou dissociação funcional do sistema nervoso, impossibilitando a contração dos músculos; êstes, embora flácidos, devem, segundo Pohl, ser considerados normais. A Comissão refuta que tais músculos sejam normais; a condição já havia recebido denominaçōes mais corretas, como paralisia temporária, paralisia por estiramento, dissociação funcional, e já fôra descrita por Robert Jones em 1911. 3) A incoordenaşão, que surge nos casos não-tratados. Para a Comissão, é apenas outro têrmo dado ao fenômeno de substituição ou "mass muscle action" de uma extremidade, de há muito conhecido pelos cirurgiões ortopedistas; ademais, a designação "incoordenação muscular" já havia sido empregada por Wilbur em 1912. 4) A paralisia, devida à morte do neurócito ocorre, mas é rara e, em geral, o suposto déficit é provocado pelo espasmo não-tratado e pela defeituosa utilização dos músculos dissociados (Poh1). Segundo o parecer da Comissão, se se prevenir as deformidades, a paralisia flácida causada pela destruição dos neurócitos é a causa primordial das seqüelas. 
A Comissão passa, depois, a tratar do método Kenny e faz a avaliação crítica do mesmo:

\section{TRATAMENTO KENNY}

1. O tratamento ativo, inclusive a reedu. caçẩo muscular, é iniciado precocemente.

2. O paciente é mantido na posição normal no leito.

3. O "espasmo" e a dor são tratados pelo emprêgo de compressas quentes, aplicadas e reaplicadas contínuamente durante cêrca de 12 horas por dia, segundo uma técnica rígida; sāo continuadas até regressão do "espasmo".

4. As extremidades são submetidas a movimentos tão amplos quanto fôr tolerado; êste processo é repetido várias vezes ao dia.

5. A reeducação muscular é iniciada tão precocemente quanto possível. Ela é dirigida no sentido de: a) restaurar a "mental awareness" dos músculos; b) restaurar a coordenação ou combater a incoordenação; c) restaurar a função muscular.

6. Não devem ser usadas talas, bandagens, ou engessamento.

7. Não devem ser usados aparelbos para respiração artificial.

8. Os pacientes e suas familias são levados a acreditar que será obtido o restabelecimento completo, ou, no caso de paralisias residuais, que o tratamento Kenny não foi instituido precocemente, ou foi administrado impropriamente.

9. Tòda melhora es atribuida ao tratamento, e não é reconhecido qualquer restabelecimento ou melhora espontâneos.

10. A balneoterapia é importante fator adjuvante dos processos pré-citados.

\section{PARECER DA COMISSÃO}

1. O inicio precoce do tratamento é desejável, mas as condições gerais do paciente na fase aguda febril podem ser de molde a tornar prejudicial o tratamento Kenny: isto e a terapêutica durante 2 fase aguda febril $\dot{c}$ primariamente um problema médico.

2. A posição apropriada no leito é prática generalizada entre médicos, há 30 anos; ainda é um processo recomendável.

3. A termoterapia tem sido usada pelos médicos há muitos anos para combater a dor na paralisia infantil; em vários casos, a dor pode ser suavizada, mas às vezes não se obtêm resultados. A dor não é, em diversas eventualidades, aspecto muito importante da moléstia e, se presente, pode ser aliviada também por outras medidas. As compressas quentes podem aliyiar o "espasmo", mas o niesmo se consegue com o repouso. Em alguns casos, as compressas parecem ter agravado o "espasmo"; em outros, êste desapareceu quando foi interrompida a aplicação das compressas. Finalmente, às vezes, após ter desaparecido com êsse processo, o "espasmo" retornava. $O$ uso das compressas não pode ser considerado uma panacéia, e deve ser guiado pelo julgamento do médico.

4. Este ponto é aceitável, se o movimento ativo e passivo das extremidades fôr realizado dentro dos limites do confôrto, e nunca deve ser forçado até o ponto de produzir dor.

5. Jones e Lovett, em 1929, descreveram e utilizaram um método de reeducação muscular semelhante, em principio, ao ensinado por Kenny; êsse processo serviu de base para o tratamento ortopédico, durante muitos anos.

6. Foram observados casos, submetidos ao tratamento Kenny, em que se estavam desenvolvendo contraturas precoces, e nos quais, pelo uso do engessamento, as contraturas foram controladas. As braçadeiras formam parte importante do tratamento nas fases tardias da moléstia e poderiam, muitas vezes, substituir as muletas inglêsas usadas por algung pa. cientes tratados pelo método Kenny.

7. Os aparêlhos para respiraçăo artificial salvaram muitas vidas e devem ser utilizados em pacientes com um grau de paralisia capaz de embaraçar a respiração.

8. Não há provas de que o tratamento Kenny evita ou diminui o grau da paralisia. Kenny afirmava, aos pacientes que lhe chegavam após tratamento em outro lugar, que, se tivessem acorrido mais cedo, a desabilidade teria sido evitada; esta afirmação não é fundada em fatos.

9. A cura espontânea da poliomielite ocorre em muitos casos; referências na literatura médica indicam que, em diferentes epidemiss, isto sucede em 50 a $80 \%$ dos casos.

10. As piscinas e os banhos têm sido usados, há muito tempo, no tratamento da poliomielite. 
A Comissão chegou às seguintes conclusões:

“1. A objeção de Kenny ao exame dos músculos e a conseqüente falta de acurados registros, são condenáveis. Se tal fôsse praticado por tôdas clínicas, não se poderiam obter estatísticas razoàvelmente corretas, nem se poderiam determinar os resultados de qualquer tipo de tratamento. Não julgamos que o exame dos músculos, se conduzido cuidadosa e judiciosamente, seja prejudicial ao paciente. Em nossas visitas a várias clínicas, não encontramos, afora Miss Kenny, quem considerasse prejudiciais os exames dos músculos.

2. Miss Kenny afirmou, repetidamente, que pelo tratamento "ortodoxo" só $13 \%$ dos pacientes se restabeleciam sem paralisia, enquanto que, sob seu tratamento, mais de $80 \%$ se curam. Cremos que isto é um deliberado falseamento dos fatos referentes ao tratamento por outros métodos. Atribuímos isto ao excessivo desejo de promover a adoção do tratamento Kenny. Sua afirmação, a respeito de $80 \%$ de restabelecimentos com êste tratamento, não é confirmada por estatísticas adequadas baseadas em significativo número de casos. A proporção atribuída ao tratamento "ortodoxo" é tirada de um artigo que trata exclusivamente de pacientes gravemente paralisados. A Miss Kenny foi repetidamente observado que esta não é uma comparação idônea ("is not a fair comparation to make") e que, se forem incluídos todos casos de uma epidemia nessa estatística, pode-se esperar 70 a $90 \%$ de restabelecimentos com tratamento "ortodoxo". Miss Kenny fêzz esta comparação inacurada em maio de 1944.

3. Alguns dos que empregam o tratamento Kenny acreditam que a paralisia pode ser evitada se o tratamento fôr iniciado com suficiente precocidade, isto é, antes do estabelecimento da paralisia. Nós vimos vários casos, contudo, em que o tratamento Kenny foi instituído muito cedo, e não nos convencemos que isto evite ou mesmo diminua o grau da paralisia permanente.

4. Em muitos casos vistos por nós a paralisia progrediu após ter sido instituído o tratamento Kenny.

5. O grau da paralisia residual depende, em qualquer caso, do grau de destruição no sistema nervoso central, quando as deformidades são evitadas, e isto varia tremendamente nas diversas epidemias.

6. Pode haver algumas alterações locais em músculos isolados durante a fase aguda, cuja natureza deve ser estudada com mais minúcias. Esta alteração, quando presente, pode ser primária nos próprios próprios músculos ou pode ser secundária a alterações no sistema nervoso central. Como Lovett salientou, as contraturas podem-se desenvolver precocemente e, se não forem evitadas ou corrigidas durante as fases iniciais, podem determinar deformidades resistentes ao tratamento. Deve-se ressaltar que a prevenção destas contraturas é o processo primário pelo qual o cuidado médico consegue diminuir os efeitos da moléstia.

7. Segundo parecer da Comissão, após observação de 740 pacientes, particularmente durante a epidemia de 1943 , a aplicaçấo contínua $e$ indiscriminada de compressas quentes é de valor discutível, constituindo desnecessário desperdício de pessoal e de leitos hospitalares. Podem ser utilizadas, com bons resultados, compresas simples. Novamente salientamos o fato de que o sadio critério médico deve ser aplicado na determinação dos casos em que o tratamento hospitalar deve ser instituído ou continuado.

8. Miss Kenny afirmou, recentemente, que podia diagnosticar a moléstia c determinar a extremidade comprometida antes do estabelecimento dos sinais clínicos usualmente utilizados para o diagnóstico. A instituição de seu método, nesta ocasião, controlaria a dor e evitaria a paralisia. Ela considerou que isto representava sua maior contribuição isolada. O diagnóstico pré-paralítico foi descrito por Draper (1931) e Aycock e Luther (1928). Não foi apresentada, a esta Comissão, uma prova satisfatória de que a instituição do tratamento local precoce consiga alterar o curso ou a extensão da paralisia em qualquer caso. 
9. Muitos dos que utilizaram o método Kenny afirmaram reiteradamente que tôdas escolioses paralíticas podem ser evitadas por tal processo. Entre os pacientes estudados por esta Comissão, durante as últimas três epidemias, não foi notada qualquer escoliose, mas apenas ligeiras curvaturas da raque. Todavia, escolioses paralíticas graves só ocorrem nas crianças em crescimento e são raras em prazo inferior a três anos após início da moléstia. Muitos anos mais devem transcorrer até que se possam tirar conclusões definitivas em relação à melhora ou prevenção da escoliose paralítica por meio do tratamento Kenny.

10. Embora a Comissão desaprove e condene a larga publicidade que confundiu o público e muitos médicos, ela reconhece que isto estimulou a profissão médica, levando-a a revalidar métodos de tratamento da poliomielite anterior aguda e contribuiu para que a mesma possa ser tratada com maior eficácia." 